\begin{tabular}{|l|l|l||}
\hline \multicolumn{2}{|c|}{ PublisherInfo } \\
\hline \hline PublisherName & $:$ & BioMed Central \\
\hline \hline PublisherLocation & $:$ & London \\
\hline \hline PublisherImprintName & $:$ & BioMed Central \\
\hline \hline
\end{tabular}

\title{
Amiodarone to prevent arterial fibrillation
}

\begin{tabular}{|l|l|l||}
\hline \multicolumn{2}{|c|}{ ArticleInfo } \\
\hline \hline ArticleID & $:$ & 4194 \\
\hline \hline ArticleDOI & $:$ & $10.1186 /$ ccf-2000-4937 \\
\hline \hline ArticleCitationID & $:$ & 4937 \\
\hline \hline ArticleSequenceNumber & $:$ & 53 \\
\hline \hline ArticleCategory & $:$ & Paper Report \\
\hline \hline ArticleFirstPage & $:$ & 1 \\
\hline \hline ArticleLastPage & $:$ & 3 \\
\hline \hline & & RegistrationDate : 2000-4-20 \\
\hline ArticleHistory & $:$ & OnlineDate \\
\hline \hline ArticleCopyright & $:$ & Current Science Ltd2000-4-20 \\
\hline \hline ArticleGrants & $:$ & \\
\hline \hline ArticleContext & $:$ & 1305422 \\
\hline \hline
\end{tabular}




\section{Keywords}

Amiodarone, atrial fibrillation, propafenone, sotalol

\section{Comments}

The results of this study demonstrate that amiodarone is twice as effective in preventing recurrences of arterial fibrillation (AF) when compared to sotalol and propafenone. It appears to be well tolerated when given in doses of $200 \mathrm{mg} /$ day for a follow up period of 1 year, and significant thyroid and pulmonary complications only occurred in a very small number of subjects. Adverse events resulting from amiodarone are known to be related to the dose and duration of treatment, and so long-term followup data (5-10 years) will be important, since AF has a relatively low absolute mortality. Larger studies are needed to show whether amiodarone therapy has any effect on mortality; this was not a primary outcome variable in this study. The authors conclude that amiodarone should therefore be used as primary therapy in AF since it is well tolerated and effective, rather than being reserved for resistant cases because of concerns over its long-term side effects.Obviously the population studied were not critically ill patients, and so these benefits may not translate into the intensive care unit (ICU). AF is a frequent dysrhythmia seen in the ICU, which is usually terminated by treatment of the underlying pathology (e.g. electrolyte imbalance, sepsis, hypovolaemia etc). However, antiarrhythmic agents are often employed in the short term to get control of the situation, and amiodarone certainly appear to be efficacious in restoring sinus rhythm in the critically ill. The results of this study may mean that amiodarone is also an effective agent at preventing recurrences of AF in the critically ill, once the underlying pathology has been stabilised.

\section{Introduction}

AF affects $5 \%$ of people over 65 years old, and results in complications such as stroke and heart failure. Restoration of sinus rhythm reduces complications and controls symptoms, but AF recurs in $50 \%$ of treated patients within 3-6 months. Class I agents have been reported to increase mortality when used to treat AF, whereas amiodarone has been shown to be more efficacious than other anti-arrythmic agents. Consequently, this study compared amiodarone with sotalol or propafenone for preventing recurrence of AF. 


\section{Methods}

. Prospective, non-blinded, randomised trial to receive amiodarone (201 patients) or sotalol/propafenone (101 patients received each drug).

. Recruited patients had had at least one episode of symptomatic AF documented electrocardiographically.

. Patients received anticoagulants if AF lasted more than $48 \mathrm{~h}$, and electrical cardioversion was performed if required.

. Dose of amiodarone following loading period $=200 \mathrm{mg} /$ day

. Minimum follow-up 1 year.

\section{Results}

The probability of remaining in sinus rhythm at follow-up was $69 \%$ in patients receiving amiodarone and $39 \%$ in those receiving sotalol or propafenone $(P<0.001)$. Mortality and major morbidity was similar in the groups but strokes and intracranial haemorrhages were reduced in the amiodarone group $(P=0.01)$. Significantly, more patients discontinued medication in the sotalol and propafenone groups because of lack of effect, but there were no differences due to adverse events. Pulmonary and thyroid toxicity were seen in four and two patients receiving amiodarone respectively.

\section{References}

1. The Canadian Trial of Atrial Fibrillations Investigators: Amiodarone to prevent recurrence of atrial fibrillation. New Engl J Med. 2000, 342: 913-920.

This PDF file was created after publication. 